\title{
FITZ-HUGH-CURTIS SYNDROME - AN UNEXPECTED DIAGNOSIS AND THE IMPORTANCE OF PREVENTION
}

\author{
Filipa Urbano1, Catarina Marques Duarte ${ }^{1}$, Carla Simão², Bárbara Matos Águas², A. Siborro de Azevedo². \\ ${ }^{1}$ Department of Pediatrics, Santa Maria Hospital, Lisbon North Hospital and University Center, Lisbon, \\ Portugal; \\ ${ }^{2}$ General Pediatrics Unit of the Medical Pediatrics Service, Santa Maria Hospital, Lisbon North Hospital and \\ University Center, Lisbon, Portugal.
}

\begin{abstract}
Fitz-Hugh-Curtis Syndrome refers to perihepatitis associated with female genital tract infection. Chlamydia trachomatis and Neisseria gonorrhoeae are the main etiological agents. A 17-year-old female presented with right abdominal pain for five days, radiating to the right shoulder associated with fever, vomiting and diarrhea. Blood tests revealed raised levels of inflammatory markers, GGT, amylase and lipase. Abdominal ultrasonography showed no abnormality but abdominal and pelvic CT demonstrated perihepatitis. The adolescent reported the practice of unprotected sex and etiological investigation revealed $N$. gonorrhoeae and $C$. trachomatis in urethral and vaginal discharge respectively. These findings were suggestive of Fitz-HughCurtis Syndrome. She was treated with azithromycin and ceftriaxone and had marked clinical improvement.
\end{abstract}

\author{
ARTICLE HISTORY \\ Received 1 September 2020 \\ Accepted 6 December 2020

\section{KEYWORDS} \\ adolescent, abdominal \\ pain, pelvic inflammatory \\ disease, sexually transmitted \\ diseases, Fitz-Hugh-Curtis \\ Syndrome.
}

\section{Introduction}

The normal adolescent psychosocial development leads to a desire for autonomy and risky behaviors. ${ }^{1}$ Besides, adolescents rarely seek health care, being vulnerable to sexually transmitted infections (STI). ${ }^{2}$ Chlamydia trachomatis and Neisseria gonorrhoeae, the main bacterial causes, rarely lead to complications if treated early. ${ }^{2,3,4,5,6}$ On the other hand, failure to treat these infections could lead to complications such as pelvic inflammatory disease (PID), epididymitis, orchitis, infertility and cervical, penile or anal cancer. ${ }^{3}$ PID is an acute or subclinical infection of the upper female genital tract resulting from an upward contamination of endocervicitis. ${ }^{3,6}$ Risk factors are age under 25 years old, sexual activity particularly with new or multiple sexual partners, personal history of STI or PID, partner with STI, consumption of alcohol, tobacco or other drugs and pelvic or uterine instrumentation. ${ }^{6,7,8}$ The use of barrier contraceptive methods is a protective factor. ${ }^{8}$ Although not pathognomonic, clinical signs have a sensitivity of $65-90 \%$ for the diagnosis of the disease, which could present with abdominal or pelvic pain, dyspareunia, vaginal discharge, metrorrhagia, fever, vomiting or pain on cervical and adnexal mobilization. $6,7,9 \mathrm{~A}$ positive result for $C$. trachomatis and Mycoplasma genitalium in the urethral or vaginal biological fluids supports the diagnosis, while the absence of vaginal discharge has an

Address for Correspondance: Filipa Urbano, Departamento de Pediatria, do Hospital de Santa Maria, Avenida Professor, Egas Moniz, 1649-035, Lisboa, Portugal.

Email: filipaurbano.int@gmail.com

(C2021 Pediatric Oncall important negative predictive value.7,8 To exclude other pathologies or complications, abdominal and pelvic ultrasound, CT or MRI may be indicated. ${ }^{6,7,9}$ Antibiotic therapy should be started early and empirically, with broad spectrum associations, combined with sexual partners' treatment and safe sex practices. ${ }^{6,7}$

The unpredictable evolution of STI may be associated with acute or chronic complications. ${ }^{6,7}$ FitzHugh-Curtis Syndrome (FHCS) is a complication of PID, occurring in $4-27 \%$ of the cases. ${ }^{3,10}$ It is characterized by perihepatitis, with pleuritic pain in the right hypochondrium, sometimes radiating to the right shoulder. ${ }^{7,9,10}$ The definitive diagnosis is made by laparoscopy or laparotomy, showing violin-string liver adhesions and the presence of microorganisms in the liver capsule. 9,10 However, the recommended procedures are the non-invasive ones, since the disease is benign, treatable with targeted antibiotic therapy and the benefits of the hepatic adhesions treatment is not demonstrated. ${ }^{7,10}$ The hepatic enhancement that appears on CT suggests the diagnosis. ${ }^{10}$ We present a 17 years old female who had perihepatitis and $N$. gonorrhoeae and C. trachomatis in urethral and vaginal discharge respectively.

\section{Case Report}

A 17-years-old adolescent, with no relevant personal history, presented with fever, vomiting, diarrhea and constant abdominal pain. On the fifth day of the disease, she went to an emergency service where the blood tests (Table 1 ) revealed an increase in inflammatory parameters (white blood cells $22.1 \times 10^{9} / \mathrm{L}$ with $88.1 \%$ of neutrophils and $\mathrm{C}$ reactive protein $12.3 \mathrm{mg} / \mathrm{dL}), \mathrm{GGT}$ (79 U/L), amylase (134 U/L) and lipase (85 U/L), with normal liver function tests and a negative immunological 
Figure 1. Peripheral hyperdensities of the liver (arrows), compatible with perihepatitis, on abdominal and pelvic $\mathrm{CT}$.

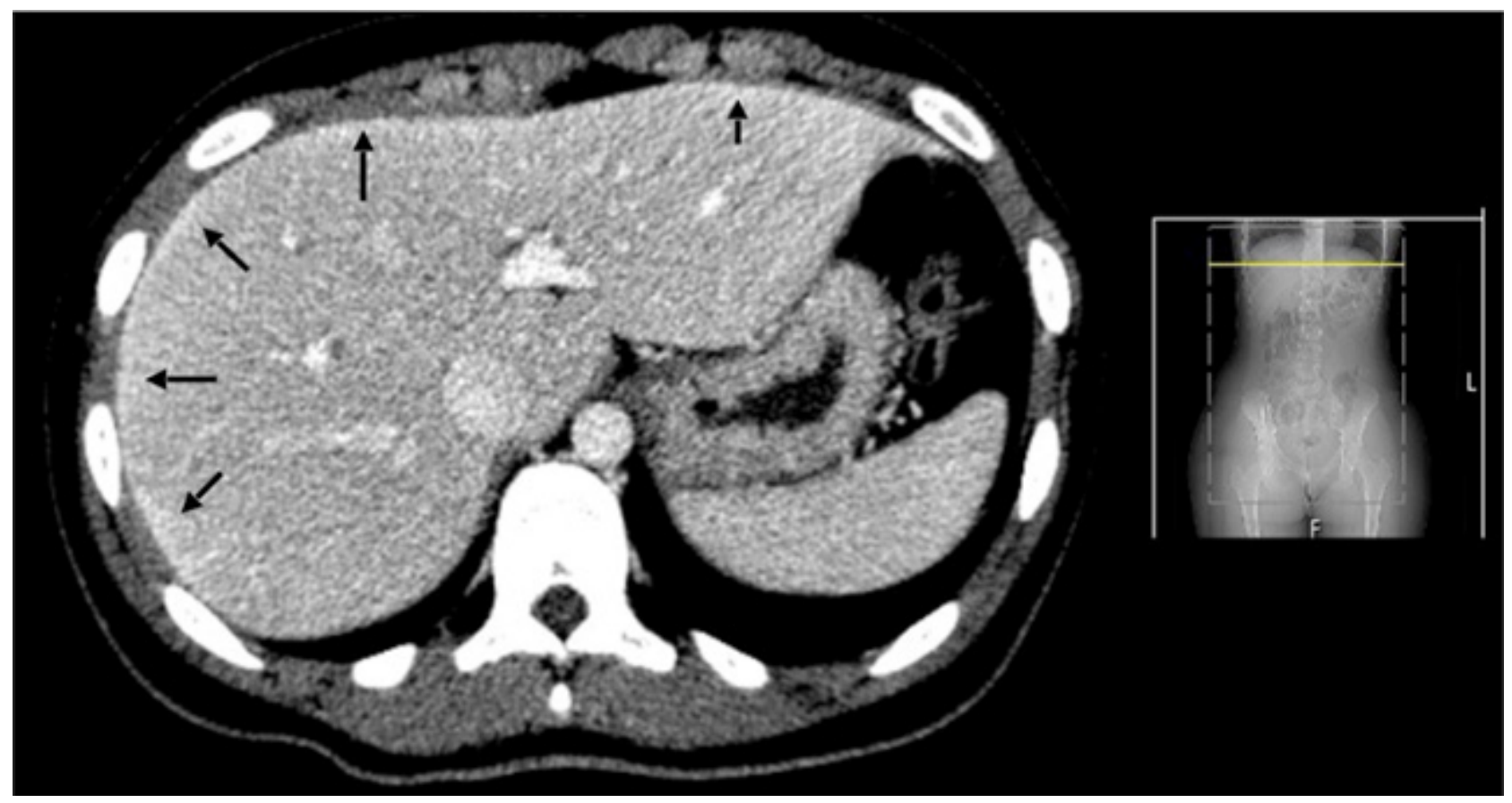

test for pregnancy. Abdominal ultrasound was normal. She was transferred to our hospital for pediatric surgery. At our hospital, she was apyretic, sometimes tachycardic but always hemodynamically stable, with periods of severe abdominal pain. Evaluation by pediatric surgeon found a decrease in the bowel sounds; right iliac fossa and right hypochondrium pain on palpation; abdominal muscle contracture and a positive Murphy and Psoas signs. The blood test results were like the previous ones. Chest radiography and abdominal ultrasound showed no relevant changes. Abdominal and pelvic CT showed perihepatitis (Figure 1) and an inflammatory process of the fallopian tubes. The patient reported regular unprotected sex with more than one partner. Integrating the clinical history with the examination findings, the diagnostic hypothesis was PID complicated by perihepatitis and FHCS. Gynecology evaluation was unremarkable. Culture of urethral discharge was positive for $N$. gonorrhoeae, PCRs for C. trachomatis and Mycoplasma hominis were positive on vaginal discharge. Other STIs (HIV, syphilis, hepatitis $B$ and $C$ and herpes simplex virus 1 and 2 infections) were excluded. She was treated with a single dose of intramuscular ceftriaxone $500 \mathrm{mg}$ plus a single dose of oral azithromycin $1 \mathrm{~g}$, followed by a second dose of oral azithromycin $1 \mathrm{~g}$ one week later. Sexual contacts screening for the last three months was recommended. Diagnosis of gonorrhea in a sexual partner was confirmed a month later follow up visit.

\section{Discussion}

Sexually active adolescents have a higher incidence of STI than adult women ${ }^{2}$ and an age appropriate clinical history is crucial for the diagnosis of these infections. FHCS should be considered in the differential diagnosis of young people with right hypochondrium pain. ${ }^{9,10}$ In this case report, the visualization of peri-hepatitis on
CT scan reinforced the diagnostic hypothesis and was confirmed by microbiological diagnosis.

The treatment of $\mathrm{N}$. gonorrhoeae infections should also involve eradication of $\mathrm{C}$. trachomatis, whose concomitant infection is relatively common. ${ }^{12}$ The combination antimicrobial therapy with extendedspectrum cephalosporins and azithromycin seems to show synergy in-vitro and in-vivo so, the recommended empirical treatment is intramuscular ceftriaxone 500 mg with oral azithromycin $1 \mathrm{~g}$, and another $1 \mathrm{~g}$ one week later. ${ }^{12}$

The risk of infertility, chronic pelvic pain and extrauterine pregnancy increases with each episode of PID. ${ }^{7}$ Nevertheless, if appropriate antimicrobial therapy is implemented early, fertility is usually preserved after the first episode of PID. ${ }^{7}$ It is therefore important that, in an opportunistic way, adolescents are informed of the risk factors for these diseases, namely unprotected sexual activity with multiple partners. $6,7,8$ In patients undergoing therapy, it is crucial to inform that they should avoid unsafe sex practices until the treatment is complete and symptoms resolved and that sexual contacts should be screened for the infection as well. ${ }^{3,7}$ Informing the population is one of the main steps for a healthy population.

\section{Compliance with Ethical Standards \\ Fundin: None \\ Conflict of Interest: None}

\section{References:}

1. UpToDate. Sexually transmitted infections: Issues specific to adolescents. Available at URL: https://www.uptodate. com/contents/sexually-transmitted-infections-issuesspecific-to-adolescents?search $=$ sexual\%20infections $\% 20$ diseases $\&$ source $=$ search_result\&selectedTitle $=2 \sim 150 \&$ usage_type $=$ default\&display_rank $=2$. Accessed on 12 
February 2019.

2. Inquérito Serológico Nacional 2015-2016: Infeções Sexualmente Transmissíveis. Outubro de 2017. Available at URL: http://repositorio.insa.pt/ bitstream/10400.18/5402/1/INSA_ISN-2015-2016-IST_ web.pdf. Accessed on 1st December 2020.

3. Grupo para o Estudo e Investigação de Doenças Sexualmente Transmissíveis da Sociedade Portuguesa de Dermatovenereologia. Infecções Sexualmente Transmissíveis - IST. 2017. Available at URL: https://www. spdv.pt/op/document/?co=209\&h=f413e\&in $=1$. Accessed on 1st December 2020.

4. Grupo para o Estudo e Investigação de Doenças Sexualmente Transmissíveis da Sociedade Portuguesa de Dermatovenereologia. Infeção genital por Clamídia. 2017. Available at URL: https://www.spdv.pt/op/ document $/ \mathrm{co}=216 \& \mathrm{~h}=7 \mathrm{e} 6 \mathrm{a} 8 \& \mathrm{in}=1$. Accessed on $1 \mathrm{st}$ December 2020.

5. Grupo para o Estudo e Investigação de Doenças Sexualmente Transmissíveis da Sociedade Portuguesa de Dermatovenereologia. Gonorreia. 2017. Availbale at URL: https://www.spdv.pt/op/ document $/ ? \mathrm{co}=215 \& \mathrm{~h}=45 \mathrm{be} 3 \& \mathrm{in}=1$. Accessed on $1 \mathrm{st}$ December 2020.

6. Sociedade Portuguesa de Ginecologia. Consenso sobre Infecções Sexualmente Transmissíveis: Endocervicites e DIPs. 2007. Available at URL: https://www.spdv. pt/_grupo_para_o_estudo_e_investigacao_das_doencas_ sexualmente_transmissiveis/. Accessed on 1st December
2020.

7. Ross J, Guaschino S, Cusini M, Jensen J. 2017 European guideline for the management of pelvic inflammatory disease. Int J STD AIDS. 2018;29:108-114.

8. UpToDate. Pelvic inflammatory disease: Pathogenesis, microbiology, and risk factors. Available at URL: https:// www.uptodate.com/contents/pelvic-inflammatorydisease-pathogenesis-microbiology-and-riskfactors? search = pelvic\%20inflammatory $\% 20$ disease \& source $=$ search_result\&selectedTitle $=3 \sim 150 \&$ usage_ type $=$ default\&display_rank=3. Accessed on 12th February 2019.

9. UpToDate. Pelvic inflammatory disease: Clinical manifestations and diagnosis. Available at URL: https://www. uptodate.com/contents/pelvic-inflammatory-disease-clinical-manifestations-and-diagnosis? search $=$ pelvic $\% 20$ inflammatory\%20disease\& source $=$ search_result\&selectedTitle $=2 \sim 150 \&$ usage_type $=$ default $\&$ display_rank $=2$. Accessed on 12th February 2019.

10. You JS, Kim MJ, Chung HS, Chung YE, Park I, Chung SP, et al. Clinical Features of Fitz-Hugh-Curtis Syndrome in the Emergency Department. Yonsei Med J. 2012;53:753-758.

11. Smith S. Sexually Transmitted Infections. In: Marcdante KJ, Kliegman RM (Eds). Nelson Essentials of Pediatrics. 7th ed. Elsevier Saunders. 2015:376-381.

12. Bignell C, Unemo M. 2012 European Guideloine on the Diagnosis and Treatment of Gonorrhoea in Adults.Int J STD AIDS. 2009;20:453-457. 